\title{
Increased quinolone resistance among typhoid Salmonella isolated from Egyptian patients
}

\author{
Fatma OI Saleh ${ }^{1,2}$, Hazem A Ahmed ${ }^{1}$, Rasha MM Khairy ${ }^{1}$, Sayed F Abdelwahab ${ }^{1}$ \\ ${ }^{1}$ Department of Microbiology and Immunology, Faculty of Medicine, Minia University, Egypt \\ ${ }^{2}$ Minia Bacteriology Laboratory, Minia, Egypt
}

\begin{abstract}
Introduction: Typhoid fever is endemic in Egypt; and quinolones are the empirical treatment of choice. There are very limited data reporting quinolone resistance among Egyptian typhoidal Salmonella isolates. We previously reported that all typhoidal Salmonella were sensitive to quinolones. This study aimed to isolate and identify typhoidal Salmonella from cases suffering from enteric fever at Minia Governorate, Egypt, determine their quinolone resistance patterns, compare them to those reported 20 years ago, and test gyr $A$ mutation as a possible mechanism for quinolone resistance.

Methodology: Stool samples from Widal-positive subjects were screened by culture on suitable media and were identified biochemically. The identified isolates were tested for resistance against three representatives of the first three quinolone generations, namely nalidixic acid (NAL), levofloxacin (LEV), and norfloxacin (NOR). The gyrA gene was amplified and sequenced to detect point mutation(s) conferring quinolone resistance.

Results: Out of 230 stool samples (from patients with Widal anti-O titers of $\geq 1 / 160), 40$ isolates were $S$. enterica serovar Typhi (97.5\%) and Paratyphi A (2.5\%). Six (15\%) isolates were resistant to at least one of the quinolones, compared to $0 \%$ in 1993 . In this regard, $15 \%, 7.5 \%$, and $2.5 \%$ of the isolates were resistant to NAL, both NAL and LEV, and all three quinolones tested, respectively. Sequencing of the gyrA gene revealed point mutations at position 83 and/or 87 of the gyrA gene only among the resistant isolates.

Conclusion: There has been an increase in quinolone-resistant typhoidal Salmonella in Egypt over time.
\end{abstract}

Key words: gyrA gene; mutation; PCR; Salmonella Typhi; typhoid fever; Salmonella Paratyphi; quinolone resistance

J Infect Dev Ctries 2014; 8(5):661-665. doi:10.3855/jidc.4111

(Received 09 August 2013 - Accepted 22 November 2013)

Copyright (C) 2014 Saleh et al. This is an open-access article distributed under the Creative Commons Attribution License, which permits unrestricted use, distribution, and reproduction in any medium, provided the original work is properly cited.

\section{Introduction}

Enteric fever is caused predominantly by Salmonella enterica subspecies enterica serovar Typhi and Paratyphi A. Typhoid, caused by $S$. Typhi, is considered a major worldwide health problem; there have been 21.6 to 26.9 million cases with at least 250,000 deaths annually [1,2,3]. Typhoid fever is endemic in Egypt. At the time of publication, fluoroquinolones are the antibiotics of choice for treatment [4].

The primary target of fluoroquinolones in Salmonella is DNA gyrase, which consists of two subunits, $\mathrm{A}$ and $\mathrm{B}$, which are encoded by gyrA and $\operatorname{gyr} B$ [5]. Resistance to fluoroquinolones has emerged in the region and represents a significant threat to typhoid fever treatment [6]. A single point mutation in the quinolone resistance determining region (QRDR) of gyrA can mediate the non-fluorinated quinolone (NAL) resistance and reduce susceptibility to fluoroquinolones (e.g., ciprofloxacin [CIP]) [7,8]. Some of the more common point mutations found to be associated with resistance to quinolones in $S$. Typhi occur in the gyrA gene at amino acid position 83 and/or $87[9,10]$.

The spread of multidrug resistance in countries of high endemicity such as Egypt is very serious $[11,12,13,14]$. There are limited data, if any, reporting quinolone resistance among Egyptian isolates of typhoidal Salmonella [15]. In this regard, we previously reported that all typhoidal Salmonella isolated from patients at Minia Governorate were sensitive to quinolones [16]. Here, we isolated and identified typhoidal Salmonella from patients suffering from typhoid fever at Minia Governorate, determined their quinolone resistance, compared it to that reported 20 years ago [16], and tested gyrA mutation as a possible mechanism for quinolone resistance. 


\section{Methodology}

Isolation and identification of typhoidal Salmonella

Stool samples were collected from 230 inpatients suffering from fever and attending Minia Fever Hospital between August 2011 and June 2012 (127 females [55.2\%]; 103 males [44.8\%]). Only 80 $(34.7 \%)$ of the patients were rural residents, while 150 $(65.3 \%)$ were urban residents. All patients had positive Widal tests (Biomed, Hannover, Germany) with anti-O titers of $\geq 1 / 160$, and had a clinical picture suggestive of acute typhoid fever. The study protocol was approved by the dean of the Faculty of Medicine and the director of the Fever Hospital. Each subject consented prior to participation. The stool samples were enriched in selenite F broth and subcultured on MacConkey's agar and/or Salmonella-Shigella agar (all from Oxoid, Basingstoke, UK) to isolate lactose non-fermenting colonies. The Salmonella isolates were identified by Gram stain and biochemical tests (action on triple sugar iron agar, motility, urease production, oxidase, indole, methyl red, Voges Proskauer, citrate utilization, and gelatin liquefaction tests) as previously described [17].

\section{Antimicrobial susceptibility testing}

The antibiotic sensitivity test to representative members of the first three generations of quinolones was performed using the Kirby-Bauer disk diffusion method [18]. The following antimicrobials were tested: nalidixic acid (NAL, $30 \mu \mathrm{g}$ ), norfloxacin (NOR, $10 \mu \mathrm{g}$ ), and levofloxacin (LEV, $5 \mu \mathrm{g}$ (Bioanalyse, Ankara, Turkey), and data were interpreted according to CLSI guidelines [19].

DNA extraction, amplification, and sequencing of gyrA gene

DNA was extracted from the study samples using a DNA extraction kit according to the manufacturer's instructions (Intron Biotechnology, Gyeonggi-do, South Korea). DNA was used immediately or stored at $-20^{\circ} \mathrm{C}$. QRDR of gyrA gene was amplified by PCR using the following primer set [20]: forward $5^{\prime}$ CGGTACACCGTCGCGTACTT $3^{\prime}$ and reverse GCCTTTAGGCAGACCGCTTT (Eurofins, Germany). Sequencing of the DNA amplicons was carried out using an automated DNA sequencer (ABI 3100 Genetic Analyzer, Darmstadt, Germany). DNA sequences of amplified regions were analyzed using commercial software (Chromas software, BioEdit, version 7.05). Sequences were compared using basic local alignment search tool (BLAST) analysis with nucleotide sequence database of gyrA under accession number AB071870 (S. enterica serovar Typhi gyrA).

\section{Results}

Prevalence of S. enterica serovar Typhi and Paratyphi

Out of 230 subjects with anti-O Widal titers of $\geq$ $160,40(17.4 \%)$ isolates were identified as typhoidal Salmonella by the biochemical identification of stool isolates. $S$. Typhi was predominant among these isolates $(97.5 \%)$, followed by $S$. Paratyphi A $(2.5 \%)$. The prevalence of typhoidal Salmonella was 9\% and $24 \%$ among males and females, respectively, while it was $13 \%$ and $26 \%$ among urban and rural residents, respectively. The mean age of all the study subjects was $30.7 \pm 10.9$ years, while the mean age of those having positive Salmonella stool cultures was $28.2 \pm 13.7$ years. The highest isolation rate was in the $11-20$ year age group (35\%), followed by the $21-30$ $(20 \%), 31-40(15 \%)$, and 41-60 (10\%) age groups, respectively, suggesting that the prevalence of typhoidal Salmonella infection decreases with increasing age.

\section{Quinolone resistance of typhoidal Salmonellae}

The susceptibility of the 40 typhoidal Salmonella isolates to a range of quinolones and fluorquinolones was examined by disk diffusion method. A total of 34 isolates $(85 \%)$ were sensitive to all tested quinolones; only six isolates $(15 \%)$ were resistant to NAL, three isolates $(7.5 \%)$ were resistant to both NAL and LEV, and one isolate $(2.5 \%)$ was resistant to all three quinolones tested.

Molecular detection of quinolone resistance mechanism using gyrA sequencing

Mutations in the gyrA gene that confer resistance to quinolones were determined by PCR and nucleotide sequencing of gyrA. This revealed mutations at position 83 and/or 87 of the gyrA gene (which confers resistance) among the quinolone-resistant isolates, but not among the sensitive isolates (Figure 1). Two examples of resistant isolates (70 and 106) are shown. Isolate 70 , which was resistant to all three quinolones, had mutations at positions 83,87 , and 110 , while isolate 106, which was resistant to NAL only, contained mutations at positions 83, 95, 110, and 119 . Sensitive isolates (190 and 120) did not show mutations at the reported sites that confer resistance. As reported previously [10], a mutation occurring at position 83 of the DNA gyrase changed Ser to Tyr, Ala, or Phe, and a mutation at position 87 changed Asp to Asn or Gly (Table 1) in the resistant strains. 
Importantly, both sensitive and resistant isolates had other mutations (at positions 95, 110, and 119) that did not change the amino acids of the protein (Table 1) and did not confer resistance to quinolones as reported [10].

\section{Discussion}

In this study, 40 typhoidal Salmonella isolates were collected from the stools of 230 Widal-positive patients suffering from acute typhoid fever, of which $15 \%$ were resistant to nalidixic acid compared to $0 \%$ in our 1993 study [16]; 7.5\% were resistant to both NAL and LEV, and $2.5 \%$ were resistant to all three quinolones (NAL, NOR, and LEV). DNA sequencing revealed point mutations at position 83 and/or 87 of the gyrA gene only among the resistant isolates; these mutations are known to confer quinolone resistance.

The objective of this study was to test a sufficient number of typhoidal Salmonella to examine their resistance to quinolones and to monitor changes over time. The main methods of diagnosing acute typhoid fever in Egypt are leucopenia with relative lymphocytosis [21] and a positive Widal test with a titer $>1 / 80$ [22]. We cultured the stools of 230 patients who had acute symptoms and Widal titers suggestive of acute typhoid fever. Blood culture may have been a more productive sample, but many of our patients refused to donate another blood sample after Widal testing and so, for ethical reasons, we obtained only stool samples for the isolation of typhoidal Salmonella.

We found a higher frequency of isolation from females $(24 \%)$ than from males $(9 \%)$, which may be attributed to the higher frequency of women than men handling and preparing food in our community, which may make females more likely to get infected than males. These data are in agreement with a previous report from Egypt [4]. However, our data disagree with another report from Egypt [14], where $62 \%$ of the cases were males. Another report from the United Kingdom [23] was, also, contradictory to our findings;
Figure 1. Nucleotide and amino-acid sequencing of gyrA gene revealed mutations at position 83 and/or 87 of the gyrA gene among the quinolone-resistant isolates but not the sensitive ones

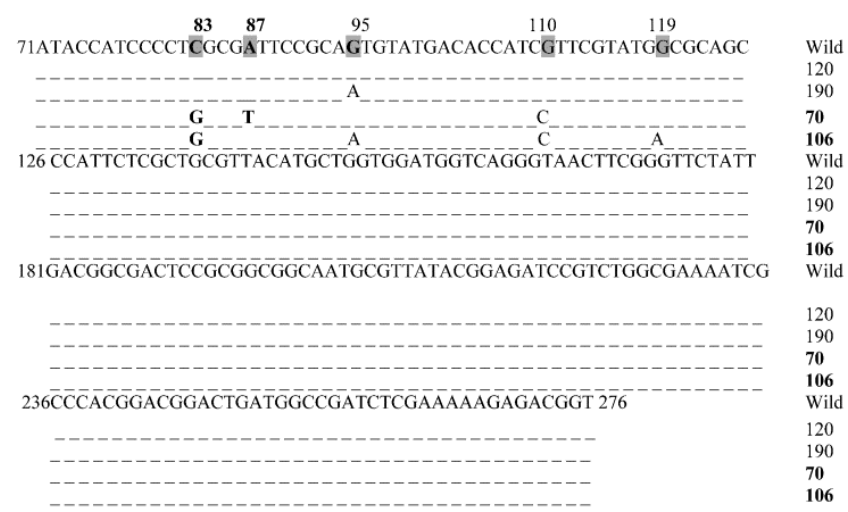

$55 \%$ of adult typhoid cases were males.

At the time of publication, fluoroquinolones are the antibiotic of choice for treatment of typhoid fever in Egypt. Resistant typhoid strains, however, have been recently reported $[9,24]$. There are limited data, if any, reporting quinolone resistance among Egyptian typhoidal Salmonella isolates [15]. We showed that NA resistance increased from $0 \%$ in 1993 [16] to $15 \%$ in this study, which was similar to what was found $(15 \%)$ in a report from Vietnam [25] and another $(16 \%)$ from Japan [26]. However, our data were contradictory to the data reported from Nepal $(76 \%$ resistance) [27], India (51\% resistance) [28], the United States (39\% resistance) [29], and South Africa (0.05\% resistance) [30]. LEV resistance in our study $(7.5 \%)$ was lower than that reported in Nepal $(73 \%)$ [31]. Together, our data show there has been an increase in resistance to the fluoroquinolones used to treat typhoid fever. These data suggest that quinoloneresistant typhoidal Salmonella increases over time in Egypt. Similar observations have been reported elsewhere [32,33].

Since fluoroquinolones are the antibiotics of choice for treatment of typhoid fever in Egypt; an alternative treatment for patients who had a resistance to quinolones is necessary. Culture and susceptibility

Table 1. Amino acid sequence of gyrA gene (at the sites conferring resistance) among the quinolone-sensitive and resistant typhoid Salmonella from Minia, Egypt

\begin{tabular}{|c|c|c|c|c|c|}
\hline Position in gyr $A$ gene & 83 & 87 & 95 & 110 & 119 \\
\hline Wild type strain AA & Ser & Asp & Pro & Cys & Ala \\
\hline Sample 120 & $-\ldots$ & $-\ldots$ & - - & $-\ldots$ & - - \\
\hline Sample 190 & - & - & - & - & - - \\
\hline Sample 70 & Tyr & Asn & - & - & - - - \\
\hline Sample 106 & Tyr & - . & - - - & - - - & - . - \\
\hline
\end{tabular}


test-guided therapy would be ideal for these patients. Alternative empirical treatments could include azithromycin and newer generations of cephalosporins (e.g., cefotriaxone or cefotamine) [12]. In this regard, until recently, there was no resistance among Egyptian isolates of Salmonella to cefotriaxone [4]. Also, there are some data from Egypt that show reemergence of chloramephenicol- and ampicillin-sensitive typhoid isolates [34], suggesting that these cheap antimicrobials could be reintegrated as a treatment option for typhoid patients. The concept of recycling old antibiotics, to which the isolates may regain sensitivity, has been recently introduced into clinical practice [35].

This study investigated the association of quinolone resistance with point mutations in the gyrA gene of typhoid isolates from Minia Governorate. The sequencing of the PCR-amplified QRDR of gyrA of the resistant strains revealed mutations at position 83 and/or 87 of the gene only among resistant isolates, and this was reflected on the protein level. Similar data have been previously reported [36].

In conclusion, there has been an increase in quinolone-resistant typhoidal Salmonella in Egypt over the last 20 years. Continuous surveillance for antimicrobial resistance should be continued to provide suitable treatment guidelines for Egyptian patients with typhoid fever. Importantly, improved sanitation and vaccine development, rather than new antibiotics, is a long-term solution to this disease.

\section{Acknowledgements}

We would like to thank the staff members of Minia fever hospital for helping with the collection of samples. Also, we would like to thank Prof. M.A. Elrehany (Biochemistry department, Minia Faculty of Medicine) for his help with the PCR testing.

\section{References}

1. Buckle GC, Walker CL, Black RE (2010) Typhoid fever and paratyphoid fever: Systematic review to estimate global morbidity and mortality for 2010. J Glob Health 2: 10401.

2. Kothari A, Pruthi A, Chugh TD (2008) The burden of enteric fever. J Infect Dev Ctries 2: 253-259. doi:10.3855/jidc. 218

3. Crump JA, Luby SP, Mintz ED (2004) The global burden of typhoid fever. Bull World Health Organ 82: 346-353.

4. Hammad OM, Abdel Wahab MF, Zaky S, Abdel Baki AM, Afify A, El Tantawi MA (2007) Multidrug resistant Typhoid fever in Egypt. Egy J Med Lab Sci 16: 57-63.

5. Piddock LJ (1995) Mechanisms of resistance to fluoroquinolones: state-of-the-art 1992-1994. Drugs 49 Suppl 2: 29-35.

6. Ghenghesh KS, Franka E, Tawil K, Wasfy MO, Ahmed SF, Rubino S, Klena JD (2009) Enteric fever in Mediterranean north Africa. J Infect Dev Ctries 3: 753-761.
7. Piddock LJ (1999) Mechanisms of fluoroquinolone resistance: an update 1994-1998. Drugs 58 Suppl 2: 11-18.

8. Turner AK, Nair S, Wain J (2006) The acquisition of full fluoroquinolone resistance in Salmonella Typhi by accumulation of point mutations in the topoisomerase targets. J Antimicrob Chemother 58: 733-740.

9. Dimitrov T, Udo EE, Albaksami O, Kilani AA, Shehab elDM (2007) Ciprofloxacin treatment failure in a case of typhoid fever caused by Salmonella enterica serotype Paratyphi A with reduced susceptibility to ciprofloxacin. J Med Microbiol 56: 277-279.

10. Eaves DJ, Randall L, Gray DT, Buckley A, Woodward MJ, White AP, Piddock LJ (2004) Prevalence of mutations within the quinolone resistance-determining region of gyrA, gyrB, parC, and parE and association with antibiotic resistance in quinolone-resistant Salmonella enterica. Antimicrob Agents Chemother 48: 4012-4015.

11. Kumar R, Gupta N (2007) Multidrug-resistant typhoid fever. Indian J Pediatr 74: 39-42.

12. Zaki SA, Karande S (2011) Multidrug-resistant typhoid fever: a review. J Infect Dev Ctries 5: 324-337. doi: $10.3855 /$ jidc. 1405

13. Wasfy MO, Moustafa DA, El-Gendy AM, Mohran ZS, Ismail TF, El-Etr SH, Oyofo BA (1996) Prevalence of antibiotic resistance among Egyptian Salmonella typhi strains. J Egypt Public Health Assoc 71: 149-160.

14. Srikantiah P, Girgis FY, Luby SP, Jennings G, Wasfy MO, Crump JA, Hoekstra RM, Anwer M, Mahoney FJ (2006) Population-based surveillance of typhoid fever in Egypt. Am J Trop Med Hyg 74: 114-119.

15. Rushdy AA, Mabrouk MI, Abu-Sef FA, Kheiralla ZH, AbdelAll SM, Saleh NM (2013) Contribution of different mechanisms to the resistance to fluoroquinolones in clinical isolates of Salmonella enterica. Braz J Infect Dis 17: 431-437.

16. Abdel-Ghafar FA, Ashour MS, Abdel-Latif HK, Kadry AA, Atia A, Fekry S (1994) Resistance patterns of clinical isolates of Salmonella and its correlation with plasmid profile. Zagazig J Pharm Sci 3: 51-57.

17. Collee J, Miles RS, Watt B (1996) Tests for the identification of bacteria. London: Churchill Livingstone. 978 p.

18. Bauer AW, Kirby WM, Sherris JC, Turck M (1966) Antibiotic susceptibility testing by a standardized single disk method. Am J Clin Pathol 45: 493-496.

19. CLSI (2011) Performance standard of antimicrobial disk susceptibility testing. Document M 100-S21 ed. Wayne, PA: CLSI.

20. Hakanen AJ, Lindgren M, Huovinen P, Jalava J, Siitonen A, Kotilainen P (2005) New quinolone resistance phenomenon in Salmonella enterica: nalidixic acid-susceptible isolates with reduced fluoroquinolone susceptibility. J Clin Microbiol 43: 5775-5778.

21. Abdel Wahab MF, el-Gindy IM, Sultan Y, el-Naby HM (1999) Comparative study on different recent diagnostic and therapeutic regimens in acute typhoid fever. J Egypt Public Health Assoc 74: 193-205.

22. Frimpong EH, Feglo P, Essel-Ahun M, Addy PA (2000) Determination of diagnostic Widal titres in Kumasi, Ghana. West Afr J Med 19: 34-38.

23. Clark TW, Daneshvar C, Pareek M, Perera N, Stephenson I (2010) Enteric fever in a UK regional infectious diseases unit: a 10 year retrospective review. J Infect 60: 91-98. 
24. Capoor MR, Nair D, Hasan AS, Aggarwal P, Gupta B (2006) Typhoid fever: narrowing therapeutic options in India. Southeast Asian J Trop Med Public Health 37: 1170-1174.

25. Wain J, Hoa NT, Chinh NT, Vinh H, Everett MJ, Diep TS, Day NP, Solomon T, White NJ, Piddock LJ, Parry CM (1997) Quinolone-resistant Salmonella typhi in Viet Nam: molecular basis of resistance and clinical response to treatment. Clin Infect Dis 25: 1404-1410.

26. Hirose K, Tamura K, Sagara H, Watanabe H (2001) Antibiotic susceptibilities of Salmonella enterica serovar Typhi and S. enterica serovar Paratyphi A isolated from patients in Japan. Antimicrob Agents Chemother 45: 956-958.

27. Khanal B, Sharma SK, Bhattacharya SK, Bhattarai NR, Deb M, Kanungo R (2007) Antimicrobial susceptibility patterns of Salmonella enterica serotype typhi in eastern Nepal. J Health Popul Nutr 25: 82-87.

28. Capoor MR, Nair D, Aggarwal P, Mathys V, Dehem M, Bifani PJ (2007) Salmonella enterica serovar typhi: molecular analysis of strains with decreased susceptibility and resistant to ciprofloxacin in India from 2001-2003. Braz J Infect Dis 11: 423-425.

29. Lynch MF, Blanton EM, Bulens S, Polyak C, Vojdani J, Stevenson J, Medalla F, Barzilay E, Joyce K, Barrett T, Mintz ED (2009) Typhoid fever in the United States, 1999-2006. JAMA 302: 859-865.

30. Smith AM, Govender N, Keddy KH (2010) Quinoloneresistant Salmonella Typhi in South Africa, 2003-2007. Epidemiol Infect 138: 86-90.

31. Shirakawa T, Acharya B, Kinoshita S, Kumagai S, Gotoh A, Kawabata M (2006) Decreased susceptibility to fluoroquinolones and gyrA gene mutation in the Salmonella enterica serovar Typhi and Paratyphi A isolated in Katmandu, Nepal, in 2003. Diagn Microbiol Infect Dis 54: 299-303.
32. Medalla F, Sjolund-Karlsson M, Shin S, Harvey E, Joyce K, Theobald L, Nygren BN, Pecic G, Gay K, Austin J, Stuart A, Blanton E, Mintz ED, Whichard JM, Barzilay EJ (2011) Ciprofloxacin-resistant Salmonella enterica Serotype Typhi, United States, 1999-2008. Emerg Infect Dis 17: 1095-1098.

33. Commons RJ, McBryde E, Valcanis M, Powling J, Street A, Hogg G (2012) Twenty-six years of enteric fever in Australia: an epidemiological analysis of antibiotic resistance. Med J Aust 196: 332-336.

34. Wasfy MO, Frenck R, Ismail TF, Mansour H, Malone JL, Mahoney FJ (2002) Trends of multiple-drug resistance among Salmonella serotype Typhi isolates during a 14-year period in Egypt. Clin Infect Dis 35: 1265-1268.

35. Arjyal A, Pandit A (2008) Treatment of enteric fever. J Infect Dev Ctries 2: 426-430. doi:10.3855/jidc. 156

36. Nobthai P, Serichantalergs O, Wongstitwilairoong B, Srijan A, Bodhidatta L, Malla S, Mason CJ (2010) Emergence and properties of fluoroquinolone resistant Salmonella enterica serovar Typhi strains isolated from Nepal in 2002 and 2003. Southeast Asian J Trop Med Public Health 41: 1416-1422.

\section{Corresponding author}

Sayed F. Abdelwahab, PhD

Associate Professor, Department of Microbiology and Immunology

Faculty of Medicine, Minia University, Minia 61511, Egypt

Phone: +20-109-000-8885

Fax: +20-86-234-2813

Email: icpminia@yahoo.com; sayed.awahab@mu.edu.eg

Conflict of interests: No conflict of interests is declared. 